\title{
Hot Analysis and Development Trends of Technology Transfer Research in Universities At Home and Abroad
}

\author{
Xiaolan Wang, Wenhao Ying ${ }^{*}$ \\ Changshu Institute of Technology, Changshu 215500, China \\ *Corresponding author.
}

\begin{abstract}
In this paper, Citespace was used to perform bibliometrics analysis of 3437 journal papers in the field of technology transfer research from 1985 to 2020 included in WOS and CNKI database. The results showed that the quantities of relevant literature on technology transfer in domestic universities has been developing gradually since 2005 and drives to maturity stage. From the perspective of research institutions, Tsinghua University has become an important institution in the field of technology transfer research in colleges and universities. Developed countries such as the United States, Britain, Germany and Italy are still the dominant subjects of technology transfer in colleges and universities, but China has surpassed Germany and Italy and become a major front for technology transfer research of universities. Future research emphasis of technology transfer of universities in China is still mainly about technology transfer performance, academic entrepreneurship, and patent. It is of great significance to promote the internationalization of technology transfer to give full play to the advantages of domestic first-class universities, actively conduct interdisciplinary studies and optimize the external environment of technology transfer.
\end{abstract}

Keywords: Technology transfer in universities, hot research, development trend

Technology transfer refers to the process of input and output of science and technology through a certain carrier between countries, regions, industries, scientific research and production, and between the science and technology system itself ${ }^{[1]}$. As one of the most important componentsof the national science and technology innovation system, technology transfer in universities is of great significance to the research of university technology transfer ${ }^{[2]}$.Many scholars at home and abroad have carried out diversified researches on the technology transfer in universities from the aspects of the factors affecting the performance of technology transfer in universities, the technology transfer mode in universities, the efficiency and evaluation of technology transfer and so on, and a great deal of research results have been accumulated so far. By using Citespace, this paper analyzes the research results of technology transfer in universities from 1985 to 2020, and discusses and reveals research hotspots and frontier trends of technology transfer in universities to presents a new approach in China.

\section{I.Data Acquisition, Application Software and Data Preprocessing}

\subsection{Data acquisition}

This paper analysed the research status of technology transfer in universities at home and abroad. Of all the articles collected in the Web of science of American ISI (Science and Information Institute (WOS) and CNKI from 1985 to 2020, 3437 papers are retrieved by using keywords technology transfer in college or university and technology transfer in universities. The data include literature types, journal sources, authors, keywords, institutions, abstracts, references. The bibliographic data derived from CNKI do not contain the information of the references ${ }^{[3]}$.

\subsection{Data preprocessing}

In this paper, based on WOS, CNKI, citespacE5.6.R5 was used to collect data on May 17, 2020. In the WOS, researchers selected "sciences citation index (SCI)" Social sciences citation index (SSCI)", "technology transfer" as 
the key word in the subject. After that, " in college or university"" was used as the key word during the secondary retrieval, 3224 literature records are obtained; selected the type of ARTICLE for literature refining, and obtained 2998 literature records. In the CNKI, researchers retrieves the subject with the technology transfer in universities as the retrieval word, and the matching method is "precision ", and 470 literature records are obtained. Because the retrieval results contain information such as news conference notices, manual screening is required when collecting data, and 439 literature records are obtained, and the exported format of records is refworks ${ }^{[4]}$.

Only 500 records are supported for export at a time in the current WOS and CNKI databases, so export process should be repeated, with export document named "download_1-500". WOS's data can be directly used for Citespace5.6.R5 analysis. By using Data preprocessing function of Citespace5.6.R5, CNKI data will be converted. By adopting word frequency analysis method, this paper analyzes the frequency and change of theme words and keywords, and determines the research hotspots and frontier trends of technology transfer in universities.

\section{Hotspots and Frontier Analysis of Technology Transfer in Universities}

\subsection{Analysis of national (regional) cooperative networks}

The researchers imported preprocessed data into Citespace5.6.R5, and set time zone from 1985 to 2020, the time interval to 1 , the network node to "author "," institution" and "country ", threshold (C, C, CCV) to,3,15 (2) $(3,3,20)$ $(3,3,20)$, data extraction object tor the top $20^{[5]}$. As shown in table 1 , the circle represents the node. The bigger the circles are, the higher the frequency of publishing scientific journals in the country (region) are. From the table 1, it is apparent that, the United States, the United Kingdom, China, Germany, Italy and other countries are the top $10^{[6-7]}$.

Table 1Publications technology transfer in universities: top 10 of the frequency of publishing scientific journals in the country $(1985-2020)$

\begin{tabular}{ccc}
\hline Nation & $\begin{array}{c}\text { frequency of publishing } \\
\text { scientific journals }\end{array}$ & betweenness centrality \\
\hline the United States & 772 & 0.57 \\
the United Kingdom & 260 & 0.23 \\
China & 250 & 0.33 \\
German & 202 & 0.09 \\
Italy & 198 & 0.12 \\
Spain & 188 & 0.20 \\
Iran & 146 & 0.14 \\
Canada & 130 & 0.08 \\
France & 105 & 0.09 \\
Netherland & 104 & 0.08 \\
\hline
\end{tabular}




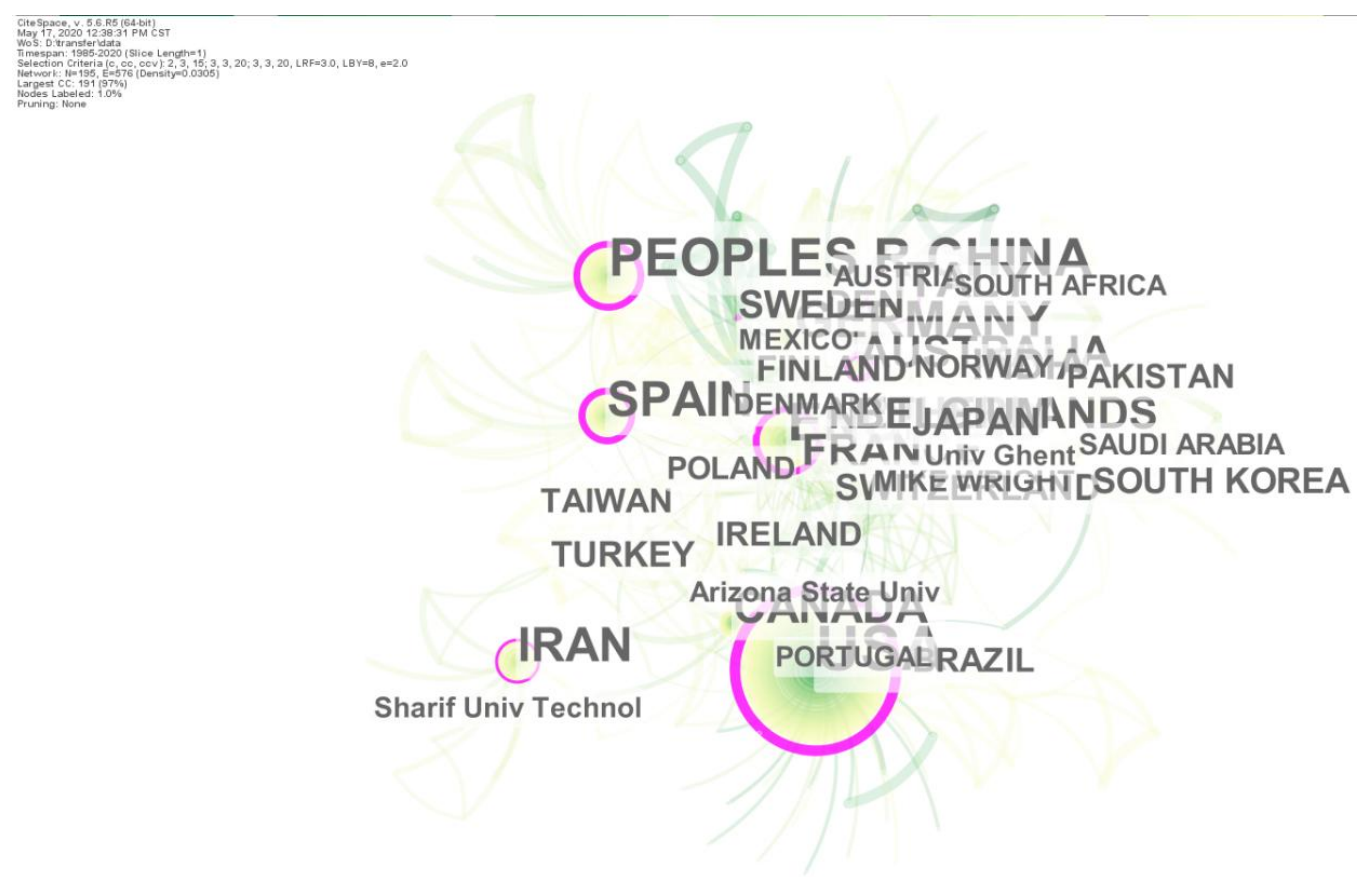

Figure 1: Mapping Knowledge Domains of technology transfer countries in universities

The results of Figure 1 showed that the United States has the largest number of publications (772) and the highest betweenness centrality (0.57), takes the absolute lead. In general, with high frequency and the intermediary center is more than 0.1 , the node is considered to be very important [9]. As can be seen from table 1, the number of Chinese publications is 250, lower than that of the UK (260); betweenness centrality (0.33) of Chinese publications, is higher than that of UK (0.23), which shows that China has fewer papers than the UK, but the overall quality and international influence of the paper is higher than that of the UK; Beyond this, Italy, Spain, Iran, Australia, Belgium, Sweden, Switzerland's betweenness centrality are bigger than 0.1 , which shows that these countries have great influence in the field of technology transfer research in universities. As seen in figures 2,3, China has fewer connections in the map than America, It shows that the international cooperation of technology transfer in universities of China is less than that in American. Viewed from research institutions, Sharif University is the institution with the most published papers (6 articles). next came Arizona State University (15 articles), In addition, the publicans frequency in Catholic University of Louvain, University of Valencia, University of Augsburg, University of California, Berkeley, University of Nottingham, And Tsinghua University and other universities are all more than 10, which shows that these colleges and universities are an important source in the research of technology transfer and have made an important contribution ${ }^{[8-10]}$. 


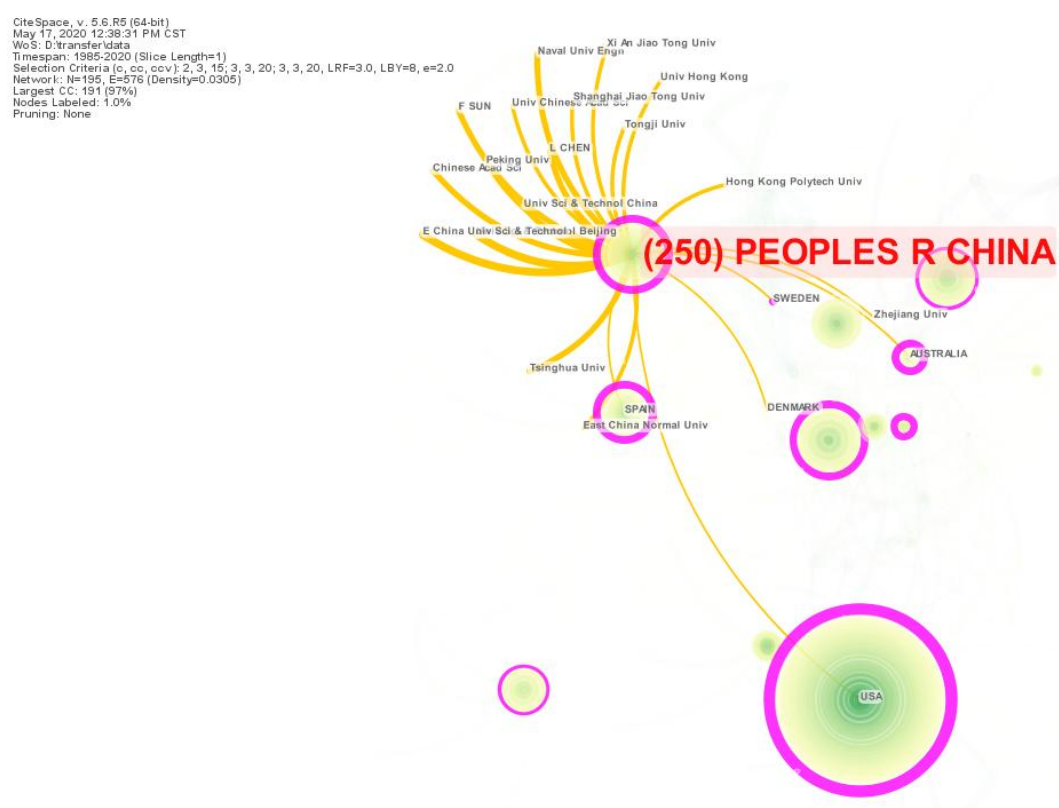

Figure 2: Mapping Knowledge Domains of technology transfer in universities of China
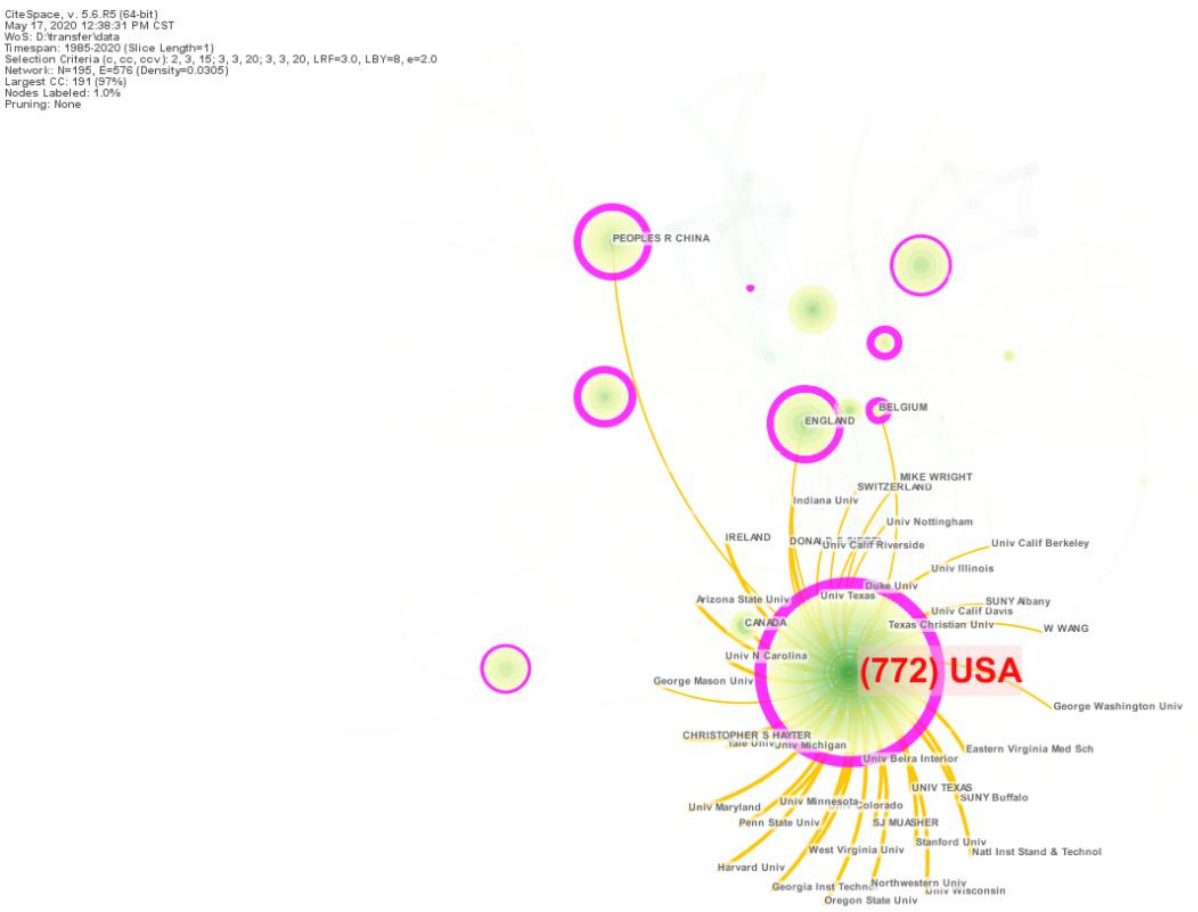

Figure 3: Mapping Knowledge Domains of technology transfer in universities of the United States

2.2 Hotspots analysisof technology transfer in universities

Research hotspots refers to the scientific problem discussed in a certain period of time by a large number of documents with internal relations ${ }^{[10]}$. Keywords accounts for little room in papers, but they are the core and essence of the whole articles. Therefore, Keywords of high frequency are often used to determine as a hotspots in a research field ${ }^{[11]}$.

The results obtained from the software operation are shown in Figure 4 that there are a total of seven large clusters

ISSN: 0010-8189 
and one of the largest clusters for the technology transfer office (\# 0); Second, vitro fertilization (\#1); in addition, innovation practice (\#2), natural convection (\#3), university research commercialization (\#4)and university spillover (\#5) all formed clusters. As can be seen from the table 2, in addition to technology transfer, innovation is the keyword which occurs more often than any other, for 467 times. However, centricity is 0.06 and higher than technology transfer, which indicates that innovation plays an important role in this field. In addition, the keyword technology appears 186 times, with 0.1 betweenness centrality, reveals that technology has the greatest influence on technology transfer in universities, and the core of which is technology. In vitro fertilization ranked second in betweenness centrality, with a value of 0.08 , indicating that this technology also has a high influence in the field of technology transfer in universities. High-frequency keywords co-occurrence network knowledge map shows (see Table 1). Research hotspots of technology transfer in universities also include knowledge transfer performance, commercialization, entrepreneurship, in vitro fertilisation, academic entrepreneurship, patent, etc
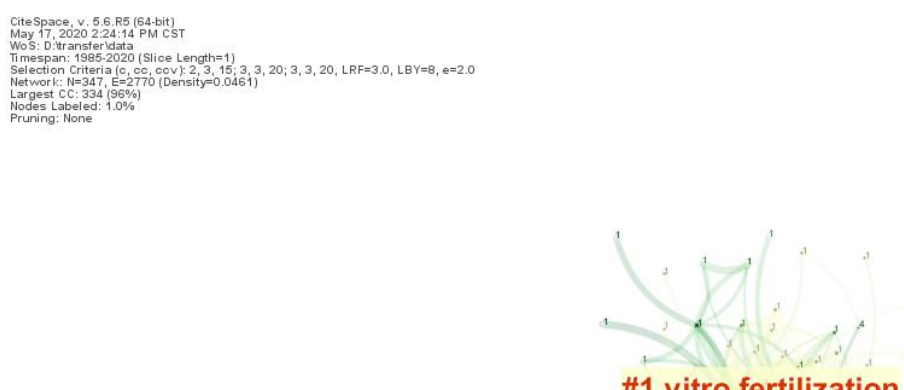

\#1 vitro fertilization \#6 southern brazil

\#2 innovation practice

\#0 technology transfer office

\#4 university research commercialization

\#5 university spillover

\#3 natural convection

Figure 4: keywords co-occurrence network knowledge map of technology transfer in universities

Table 2 High frequency keywords of literature of technology transfer in universities(top 20) (1985-2020)

\begin{tabular}{cccccc}
\hline High frequency keywords & frequency & centrality & High frequency keywords & frequency & centrality \\
\hline Technology transfer & 701 & 0.05 & entrepreneurship & 180 & 0.02 \\
innovation & 467 & 0.06 & Research and development & 171 & 0.07 \\
performance & 348 & 0.05 & impact & 159 & 0.06 \\
Bv university & 327 & 0.01 & firm & 153 & 0.02 \\
knowledge & 249 & 0.04 & In vitro fertilization & 122 & 0.08 \\
science & 228 & 0.04 & model & 122 & 0.03 \\
industry & 227 & 0.04 & Academic entrepreneurship & 114 & 0.02 \\
Knowledge transfer & 217 & 0.01 & Heat transfer & 113 & 0.07 \\
Commercialization & 201 & 0.03 & System & 112 & 0.05 \\
technology & 186 & 0.10 & patent & 107 & 0.01 \\
\hline
\end{tabular}

2.3 Frontier and development trend of technology transfer in universities

Using the expansion word detection technology and algorithm provided by Citespace5.5.6.R5 software, by investigating the time distribution of word frequency, the words with high frequency change rate are detected from

ISSN: 0010-8189 
the keywords. Based on the change trend of word frequency and frequency, the research frontier and development trend are determined ${ }^{[12]}$.

Importing the preprocessed data in Citespace5.5.6.R5, researchers set ' burst terms 'in the term type of the function and parameter area ' term type ', and ' keywords ' in the network node. The Other settings are the same as above. The results of software operation are shown in Figure 5. From the results, it can be seen that the highest change rate of keywords is ' technology transfer ', which first appeared in 1992 with a mutation rate of 17.4652, indicating that technology transfer has been concerned deeply in the academic circles of colleges and universities since 1992. "In vitro fertilization" is second only to technology transfer. This keyword first appeared in 1992, with a mutation rate of 12.6649, and then appeared again in 1999, with a mutation rate of 16.1278 and a mutation rate of 3.7773 in 2001. The data show that in vitro fertilization is an important frontier and development trend in the field of technology transfer in universities. It can be seen from Figure 5 that the field of obstetrics and gynecology occupies three co-existing fields, which is consistent with the emergence of high frequency in vitro fertilization, indicating that the field of technology transfer in universities of in vitro fertilization technology has a broad development prospect.

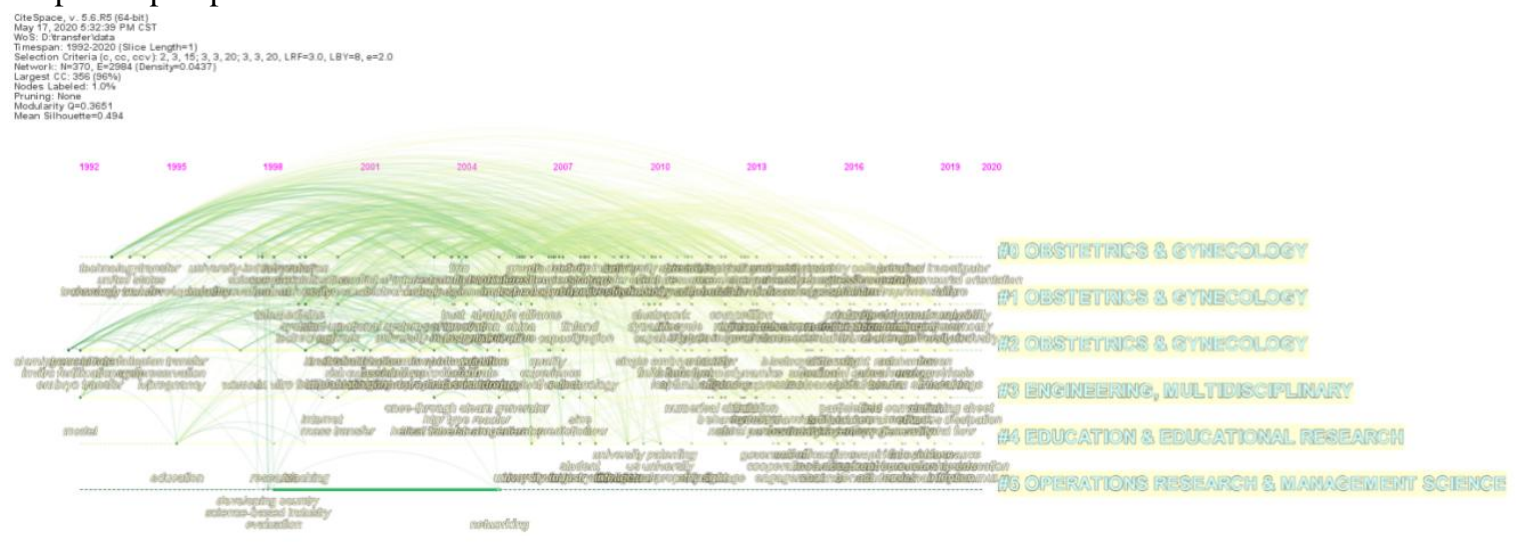

Figure 5:Map of Co-occurrence Analysis in the Field of University Technology Transfer

\section{Co-citation Analysis of Literature on Technology Transfer in Universities}

Citation refers to the previous research results cited by scholars in their papers and listed in the papers in the form of references. Citation analysis is the basis of literature co-citation and coupling analysis. Literature co-citation analysis in the field of university technology transfer research can find the knowledge base of university technology transfer research. Co-citation analysis includes literature, journals, authors, and subject co-citation analysis. When both articles A and B are cited by the third literature at the same time, that is to say, there is a co-citation relationship between $\mathrm{A}$ and $\mathrm{B}$, and the literature often cited at the same time, indicating that the concept, theory or method of the research topic is related. In the co-citation analysis, the higher the frequency of literature co-citation is, the stronger the correlation is. Based on the citation analysis of research papers in the field of university technology transfer included in WOS and CNKI databases from 1985 to 2020, this paper reveals the knowledge base of research hotspots.

Importing the preprocessed data in Citespace5.5.6.R5, researchers set network nodes to ' reference ', other settings are the same as the previous. Run the software to generate the document co-citation knowledge map (as shown in figure 6), generate 256 nodes and1149 links. The nodes represent the co-citation literature, and node size shows the frequency of literature:the larger the node is, the higher the frequency is, indicating that it is becoming increasingly important in the field of technology transfer research in universities.

The co-citation network clustering knowledge map of university technology transfer literature shows that a total of seven large clusters are generated, of which the largest cluster (\# 0) has 58 members, and the silhouette value is 
0.725. The method of log-likelihood ratio(LLR) is used and the generated label is British universities; the TFIDF is used and the generated label is university-level entrepreneurship. The most active cluster is "The role of university Knowledge Transfer Offices: Not just commercialize research outputs!” published by Zhou Ruoying (2020) in the journal< TECHNOVATION>.

Through the expansion word detection technology and algorithm, the top five mutation rates are Perkmann M (\# 5 ), with the mutation rate 49.61; Siegel DS ( \# 6 ), with mutation rate 30.47 ; Di Gregorio D (\#6), with mutation rate 26.55; Rothaermel FT ( \# 5 ), mutation rate 25.88 ; Grimaldi R (\#7), mutation rate 25.82. In addition, the mutation rates of Agrawal, D 'Este P, Shane S and O 'Shea RP in cluster 6 exceeded 20.
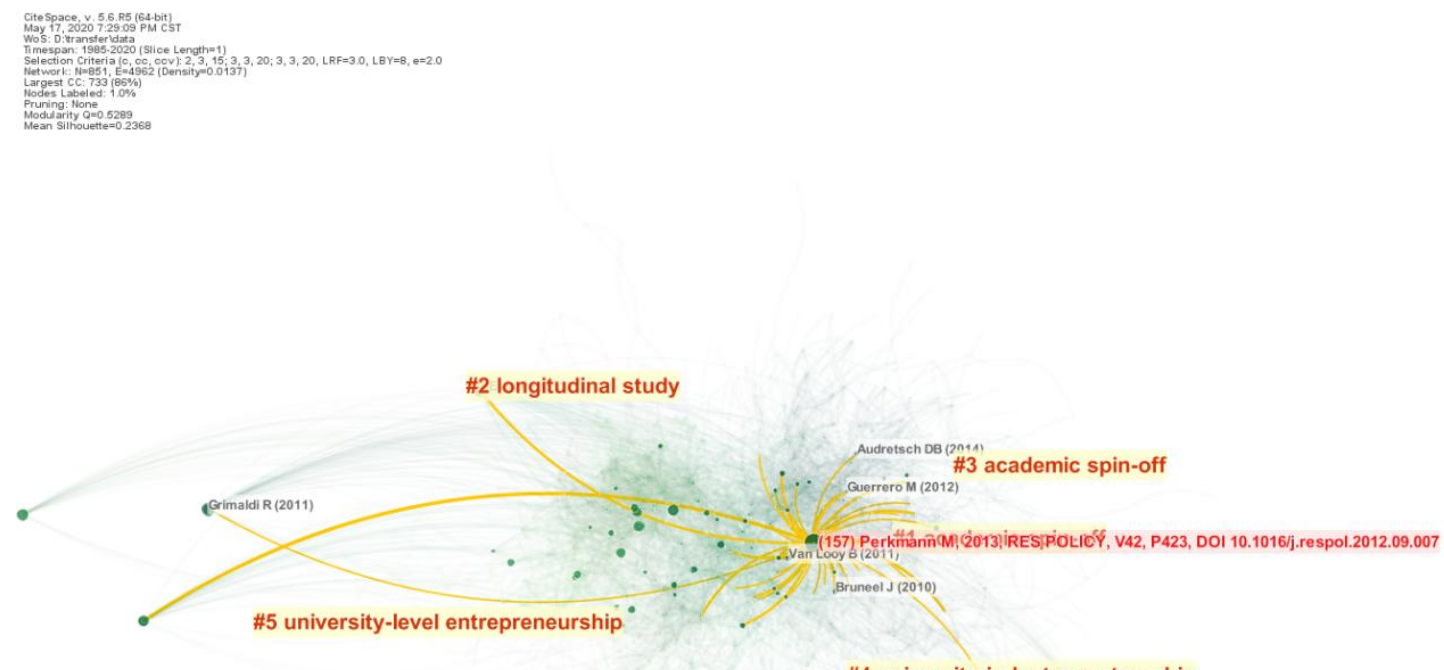

\#0 public research organisation

\#7 underlying academic tension

Figure 6: Citation network clustering map in the field of university technology transfer

Table 3 The most influential citation literature in the field of university technology transfer(1985-2020)

\begin{tabular}{|c|c|c|c|c|c|}
\hline $\begin{array}{l}\text { citation } \\
\text { frequency }\end{array}$ & centrality & the first author & year & Topics & source \\
\hline 157 & 0.15 & Perkmann M & 2013 & $\begin{array}{c}\text { Academic engagement and } \\
\text { commercialisation: A review of the } \\
\text { literature on university-industry } \\
\text { relations }\end{array}$ & $\begin{array}{l}\text { RESEARCH } \\
\text { POLICY }\end{array}$ \\
\hline 100 & 0.08 & $\begin{array}{l}\text { Rothaermel } \\
\text { FT }\end{array}$ & 2007 & $\begin{array}{l}\text { University entrepreneurship: a taxonomy } \\
\text { of the literature }\end{array}$ & $\begin{array}{l}\text { INDUSTRIAL AND } \\
\text { CORPORATE } \\
\text { CHANGE }\end{array}$ \\
\hline 93 & 0.17 & D’Este Pablo & 2011 & $\begin{array}{l}\text { Why do academics engage with } \\
\text { industry? The entrepreneurial university } \\
\text { and individual motivations }\end{array}$ & $\begin{array}{l}\text { JOURNAL OF } \\
\text { TECHNOLOGY } \\
\text { TEANSFER }\end{array}$ \\
\hline 89 & 0.07 & Grimaldi Rosa & 2003 & $\begin{array}{l}\text { Assessing the impact of organizational } \\
\text { practices on the relative productivity of } \\
\text { university technology transfer offices: an } \\
\text { exploratory study }\end{array}$ & $\begin{array}{l}\text { RESEARCH } \\
\text { POLICY }\end{array}$ \\
\hline
\end{tabular}




\begin{tabular}{|c|c|c|c|c|c|}
\hline 86 & 0.08 & $\begin{array}{l}\text { Siegel Donald } \\
\text { S }\end{array}$ & 2011 & $\begin{array}{l}30 \text { years after Bayh-Dole: Reassessing } \\
\text { academic entrepreneurship }\end{array}$ & $\begin{array}{l}\text { RESEARCH } \\
\text { POLICY }\end{array}$ \\
\hline 81 & 0.04 & O’Shea RP & 2005 & $\begin{array}{l}\text { Entrepreneurial orientation, technology } \\
\text { transfer and spinoff performance of U.S. } \\
\text { universities }\end{array}$ & $\begin{array}{l}\text { RESEARCH } \\
\text { POLICY }\end{array}$ \\
\hline 76 & 0.03 & Bercovitz J & 2004 & $\begin{array}{l}\text { Academic entrepreneurship: University } \\
\text { spinoffs and wealth creation. } \\
\text { Cheltenham: Edward Elgar }\end{array}$ & ORGAN SCI \\
\hline 75 & 0.08 & Shane S & 2007 & $\begin{array}{l}\text { University-industry linkages in the UK: } \\
\text { What are the factors underlying the } \\
\text { variety of interactions with industry? }\end{array}$ & $\begin{array}{l}\text { NEW HORIZ } \\
\text { ENTREP }\end{array}$ \\
\hline 70 & 0.05 & D’Este P & 2003 & $\begin{array}{l}\text { Why do some universities generate more } \\
\text { start-ups than others? }\end{array}$ & $\begin{array}{l}\text { RESEARCH } \\
\text { POLICY }\end{array}$ \\
\hline 63 & 0.15 & Di Gregorio D & 2008 & $\begin{array}{l}\text { Academic Entrepreneurs: Organizational } \\
\text { Change at the Individual Level }\end{array}$ & $\begin{array}{l}\text { RESEARCH } \\
\text { POLICY }\end{array}$ \\
\hline
\end{tabular}

\section{Conclusion}

Based on Citespace5.6.R5, this paper applied word frequency statistics, cluster analysis, co-citation analysis and other methods to conduct a panoramic description of the literature on university technology transfer included in the WOS and CNKI databases from 1985 to 2020(Table 3), and makes a panoramic description from the perspectives of published countries ( regions ), institutions, keywords, and citations, and sorts out the hotspots, frontiers and development trends in the field of university technology transfer research in the past 36 years. The results show that the number of literature on technology transfer in domestic universities has been developing gradually since 2005 and drives to maturity stage. Viewed from research institutions, Tsinghua University has become an important institution in the field of university technology transfer research. Developed countries such as the United States, Britain, Germany and Italy are still the dominant subjects of university technology transfer, but China has now surpassed Germany and Italy and become a major front for university technology transfer research. It is worth mentioning that Iran's Sharif University College of Technology outstriped some world-class universities, in the field of university technology transfer research. The research hotspots of technology transfer in universities have evolved from the initial technology transfer, innovation, spillover effect to the research on performance, academic entrepreneurship, commercialization of university research, and patent. The connections between countries (regions) and institutions have become increasingly close. These findings provide the following insights for that China should focus on the performance, academic entrepreneurship, school-enterprise cooperation, patent, and other aspects. Furthermore, more attention on building theories, methods, institution, mechanisms, strengthening international cooperation and deepening research on strategic alliances should be paid in the field of technology transfer research. Finally, what is now needed to be done is considerably to give full play to the advantages and responsibilities of first-class universities, actively organize interdisciplinary research, optimize the external environment, and strive to promote the internationalization development of technology transfer in domestic universities.

\section{Acknowledgements}

This paper is one of the achievements of Universities Research Project of Philosophy and Social Sciences 'Research on Data Mining of University Science and Technology Management Oriented to Decision' (2019SJA1301) in Jiangsu Province. Project leader: Wang Xiaolan. 


\section{References}

[1] C. Chen,M.Song. "Visualizing a field of research: a methodology of systematic scientometric reviews," PLoS ONE, vol.14, no. 10, pp. e0223994, 2019.

[2] M. Perkmann,V. Tartari,M. McKelvey,et al.,"Academic engagement and commercialisation: A review of the literature on university-industry relations," J. Research Policy, vol. 42, no. 2, pp. 423-442, 2013.

[3] F. T. Rothaermel,S. D. Agung, L. Jiang"University entrepreneurship: A taxonomy of the literature," J. Industrial and Corporate Change, vol. 16, pp. 691-791, 2007.

[4] P. D'este, M. Perkmann."Why do academics engage with industry? The Entrepreneurial University and individual motivations," J. Technol. Transf, vol. 36, no. 3, pp. 316-339, 2011.

[5] R.Grimaldi, K. Martin, S.Donald. "Siegel, Mike Wright. 30 years after Bayh-Dole: Reassessing academic entrepreneurship,” J. Research Policy,vol. 40, pp.1045-1057, 2011.

[6] D. S.Siegel, W.David, L.Albert. "Assessing the impact of organizational practices on the relative productivity of university technology transfer offices: an exploratory study,” J. Research Policy, vol. 32, pp. 27-48, 2003.

[7] Y. Zhao, J. J. Xu, J. C.Wu. "A New Method for Bad Data Identification of Oilfield Power System Based on Enhanced Gravitational Search-Fuzzy C-Means Algorithm," IEEE Transactions on Industrial Informatics, vol. 15, no. 11, 2019.

[8]Y. I. Na; J. J.Xu,L. M. Yan, et al.,"Task optimization and scheduling of distributed cyber-physical system based on improved ant colony algorithm," Future Generation Computer Systems, vol. 109, pp. 134-148, 2020.

[9] J. J.Xu, B.Wang, L. M.Yan, et al., “The Strategy of the Smart Home Energy Optimization Control of the Hybrid Energy Coordinated Control," Transactions of China Electrotechnical Society, vol. 32, no. 12, pp.214-223, 2017.

[10] Y. K. Xu. "Development of Ultrasonic Small Flow Measuring Instrument Based on STC89C52. 2019 2nd International Conference on Safety Produce Informatization," IEEE. Chongqing, Nov. 28-30, pp. 394-397, 2019.

[11] J.Xu, L. Huang,S.Yin, et al., “All-fiber self-mixing interferometer for displacement measurement based on the quadrature demodulation technique," Opt Rev,vol. 25, no. 1, pp. 40-45, 2018.

[12] L. C. Zhu, J. J. Xu, L. M. Yan. "Research on congestion elimination method of circuit overload and transmission congestion in the internet of things," Multimedia Tools and Applications, pp. 1-20, 2016. 